\title{
The Influence of the Traditional Teaching Approach Transfer to Flipped Classroom Approach on Dyslexia
}

\author{
Yongyi Chen ${ }^{1, *}$ \\ ${ }^{1}$ School of HongKong Education University, HongKong, China \\ ${ }^{*}$ Corresponding author. Email: s1114225@s.eduhk.hk
}

\begin{abstract}
Many studies have shown that the development of teaching methods and the influence factors of dyslexia have something in common for learners. However, the influence of the teaching approach on dyslexia remains unclear and still has details that need to be further studied. In this study, I attempt to review the influence of the traditional teaching approach transfer to flipped classroom approach on dyslexia through various literary theories. I expected to find out flipped classroom approach influences dyslexia, and flipped classroom approach can help learners with dyslexia. In practice, it can help learners with dyslexia or educators who treat dyslexia.
\end{abstract}

Keywords: Flipped classroom, Dyslexia, Teaching approach, Individual differences. Audio-visual stimulation

\section{INTRODUCTION}

Dyslexia is one of the very common types of learning disabilities frequently $[1,2]$. Some scholars believe that dyslexia is very common, affecting more than $10 \%$ of the population or $6 \%$ to $17 \%$ of the schoolage population $[3,4]$. The occurrence of dyslexia can cause children to become detached from their peers [5], which may also effects and reactions between dyslexic children and their home environment [6]. That leading to social problems at last.

Because reading skills are fundamental to personal development, children with dyslexia have special learning needs, such as more support from teachers. However, most of this is provided through specialized agencies now [5]. Also, children with dyslexia still have trouble learning to read despite traditional education or instruction $[4,7]$.

\section{THE CONCEPT OF DYSLEXIA}

\subsection{Definition}

Dyslexia is a cognitive disorder [8], specifically dyslexia that learners have in word recognition, spelling, writing, and comprehension [9]. Certain language processing areas of the brain are affected, making it difficult to acquire reading, spelling, or writing skills
[10]. Students with dyslexia need special adjustments to the text and text environment to read better[11, 12].

Dyslexia has some warning signs included recognizing letters, letter inversion, missing words, letter confusion, difficulty in understanding sounds and letters, delay in remembering numbers or letters, difficulty in following instructions and learning routines, and difficulty in creating words with sounds and slow reading or easy to forget the words they have learned [13]. More researchers regarded that dyslexia is not limited to a channel by single but a reflection of audio-visual integration incomplete. Reading requires a combination of form and sound, and it is a comprehensive process of audiovisual processing [14].

\subsection{Features}

As mentioned above, factors that affect dyslexia include words and reading strategies, auditory processing, and visual processing [15]. Reading is a process of interaction between visual and auditory channel information, which requires learners to integrate two sensory inputs to produce a perceptual experience. Dyslexia is a process by which defects appear [16]. Visual working memory is the most important part of our perceptual evaluation, diagnosis, and correction of learners' dyslexia [17]. Hearing and vision affect most learners with dyslexia. As the main mechanism of 
dyslexia, speech binding defects may be a potential cause of more basic audiovisual processing defects [18].

\section{TRANSITION OF TEACHING}

\subsection{The difference between traditional teaching method and flipped classroom}

The classroom is still teacher-centered in the traditional teaching process, and what is truly studentcentered is just empty talk [19]. On the contrary, the flipped classroom educators give students more freedom, putting the teaching process of knowledge outside the classroom, allowing students to accept new knowledge more appropriately. Then they put the process of knowledge internalization in the classroom to communicate more between students and teachers [19]. It has been found that the test scores of flipped classroom teaching are higher than those of traditional lecture-style classrooms [20].

The transition from instructive teaching to studentcentered learning has played a key role in most reforms of the modern education system. The key to this new paradigm is student participation and a more active role, and a new learning and teaching methods promote or assist self-learning [21]. Meanwhile, e-learning which market is growing every year, and the structure of education programs that use distance learning technology or e-learning has developed into an independent form of learning [22]. To sum up, these innovations (different from the traditional teaching approach) enable us to educate more effectively and use digital technology to break the paradigm of old pedagogy [23].

\subsection{Flipped classroom}

The flipped classrooms are face-to-face courses in school after studying at home, attracting people's interest [24]. They allow us to think outside the box and introduce new teaching methods into the classroom. An increasingly popular method is the flipped classroom method [25].

The flipped classroom is completely defined as extracurricular activity time when students are responsible for preparing materials for classroom activities. These activities can be watching videos, reading interactive textbooks, etc.; students can then collaborate with peers and each other in an active learning environment to apply learning materials [26, 27]. The COVID-19 pandemic has forced many colleges and universities to stop face-to-face campus operations and move research and all types of teaching online [28]. Whether it is the general environment or the needs of learners with dyslexia, flipped classrooms are a good choice for learners.
We can use resources to change dyslexia to restore children's confidence in learning and a better educational environment [6] and help students with dyslexia spelling through the use of computer vision and audio colors, graphics, music, etc. [29]. For example, Hamid proposed a computer-based research learning model to support students with dyslexia [30]. Thus, the development of new computer-based learning methods is very important to solve the learning difficulties of dyslexia [30].

Studies have demonstrated significant differences between dyslexic children and normal children in terms of positive visual short-term memory. The more complex the material, the more obvious the deficiency of children with dyslexia [31]. This complexity comes from the visual, sound, form, meaning of text characters, and complex matching relationship [32]. The flipped classroom simplifies complex reading materials by optimizing materials, helping children with dyslexia to absorb the same knowledge as normal children. Different from traditional literacy teaching, only fonts are displayed, making it difficult for children to generate automatic phonetic, shape, and meaning connections based on complex fonts.

Besides, text animation's visual and phonological matching relationship is complicated, and the multisensory channel training method has advantages. The rich visual pathway stimulation makes the multi-sensory channel training method better match the relationship. It is helpful for students to make paired associations in the process of reading and writing to obtain better learning results[33]. The flipped classroom can alleviate learners' problems in this aspect through vivid animations, videos, and sounds in the classroom. Even if they don't understand it from the first time they join, they can replay the class repeatedly.

\section{THE IMPACT OF FLIPPED CLASSROOMS}

The flipped classroom has become a popular, blended learning method [34-36]. It is one of the contemporary teaching methods. It usually means a teaching mode that students treat video lectures and practice questions as pre-class assignments and conduct student-centered activities in the classroom [37]. The shift from a traditional teaching approach to the flipped classroom may impact dyslexia.

\subsection{Visual and auditory stimulation of the flipped classroom}

There are two decisive components of a flipped classroom: the transfer of lectures outside the classroom, usually through some electronic means, and the transfer of practical application assignments (previous homework) to the classroom [38]. Traditional 
classroom learners need to review knowledge and apply it to homework outside the classroom [39]. If people with dyslexia cannot understand or read the materials given by the teacher in a traditional classroom, they will not be able to complete their homework well. The traditional teaching approach poses great challenges to learners with dyslexia.

Sarpudin and Zambri showed that students with dyslexia could read better and more easily through information and communication technology [11]. It has become a new way of teaching and learning for special needs, which can help people with dyslexia improve teaching and learning efficiency. Specifically, in the classroom, technical content is delivered through online video before class. Then students come to class and prepare to actively apply this knowledge to solve problems or do other activities [40]. A study was found among students who felt very confident after watching the video and coming to the classroom to participate in class activities instead of just watching the video [41].

Furthermore, the speech therapists suggested working on an intelligent technique to keep learners motivated, which among the proposed recommendations to improve the educational activity are to add more subjects. For example, it can be added more multimedia contents, including pictures, sounds, videos, and colorful graphics [4]. The flipped classroom can provide videos for reading and listening, pictures for reading and speaking, and small programs can be designed for matching words and sounds. Similarly, Uchiyama et al. also agreed that flipped classrooms enable learners to learn by watching videos or using other materials outside the classroom. Then they review and apply this knowledge in the classroom [39].

Learners with dyslexia need a lot of audiovisual stimulation, and it just happens that flipped classrooms can meet the needs of learners through online multimedia. Learners with dyslexia can watch videos and dynamic online content continuously for a lot of time at home. Students need to prepare for face-to-face courses by watching videos, learning-related materials, and even answering quizzes at home [42]. They can seek help in classrooms when they encounter unreadable articles or words that easily be made mistakes. It can gradually alleviate their reading difficulties.

At the same time, learners with dyslexia can read the video and listen to the audio many times to learn. They also can deepen their understanding through the small interactive programs in the flipped classroom. Online games and other technologies are auxiliary tools to help learners with dyslexia overcome dyslexia. They can promote the learning process and help them learn effectively [4]. Many studies on cognitive deficit training have shown that students' performance can be significantly improved if the intervention and assistance tasks use acoustic and visual modes at the same time [43].

Through the characteristics of the flipped classroom and those of dyslexics, we can find out the commonality that flipped classrooms' visual and auditory stimulation can alleviate the condition of dyslexics. When dyslexia carries out a lot of learning through flipped classroom, dyslexia absorb knowledge from a single channel to a multi-channel. It means they acquire information from both visual channels and auditory channels at the same time. The flipped classroom, which involves video, audio, and pictures, etc., will stimulate learners' visual and auditory organs to the greatest extent and achieve the learning effect.

\subsection{Teacher-student interaction of the flipped classroom}

Flipped classroom provides more opportunities and more creative teaching methods for transforming teaching and learning to student-centered learning [44].

In flipped classrooms, students tend to be more active compared with conventional classrooms. Zainuddin and Attaran show that flipped classrooms are more attractive than traditional classrooms, and most students have a positive attitude towards this new teaching model [45]. Students feel embarrassed to raise their hands because they are afraid to make mistakes, so they are more willing to be passive in the classroom and flipped classrooms allow them to participate in classroom activities while feeling safe [40]. In flipped classrooms, they can answer teachers' questions either through private messages or by speaking publicly. And if they need some help, they don't need to wait for a time break or line up to ask questions. Also, the teacher can repeat some detailed points that students didn't understand through auditory simulation instead of in the traditional public classroom. In particular, the learners with dyslexia are more passive when they fail to see the materials given by the teacher or misunderstand the content of the article, which may lower their learning effectiveness and lead to a bad cycle. Even students at the same level of performance may not actively answer the teacher's questions for fear of making a mistake. Students who are more dyslexic are more likely to make mistakes and lose confidence in traditional classes. With flipped classrooms, they can communicate with the teacher or answer questions individually, even if they make mistakes. Therefore, the flipped classroom has advantages over traditional teaching. If students watch the video before class, they will gain knowledge earlier and prepare for class discussion. If they do not watch the video outside of class, their knowledge of in-class activities is zero [45].

Students usually learn content online by watching video courses at home, and teachers discuss with 
students to solve homework or problems in class. The interaction between teachers and students is more personalized to guide instead of teaching [36]. However, the inversion of the flipped classroom includes multimedia (videotapes and PowerPoint lectures with audio recordings), which can be watched outside of class in the media laboratory or at home. And after absorbing knowledge at home, learners with dyslexia can return to school to discuss with teachers and classmates, which increases teacher-student interaction, active participation, and group collaboration [46].

\subsection{Personalized Development of Students in the flipped classroom}

Flipped classroom allows learners to communicate through visual, auditory, and voice channels to achieve personalized interaction with tools and improve students , motivation and performance [47].

The flipped classroom is a kind of classroom that builds in-depth knowledge. Students are the protagonists of the classroom [48]. Students in the flipped classrooms have a greater responsibility to study on their own such as controlling the lesson on the video outside the class. They can watch, pause and replay the video according to their needs [45]. When learners with dyslexia conduct audiovisual learning through flipped classrooms in advance, they can understand the course content and even familiarize themselves with the learning content before class offline. It can make their learning easier while eliminating learning disabilities, and at the same time, their symptoms will gradually decrease, or their confidence and learning motivation may increase accordingly.

In a flipped classroom, teachers record their lecture videos and assign them to students to watch them outside of class at their own pace. Students can learn according to their own needs. Each student has personalized learning [45]. Students with dyslexia can choose courses of the corresponding difficulty according to their own ability, from simple to complex step by step. For example, a student with mild dyslexia could choose to study a beginner's course (if the campus's flipped classes are graded), repeatedly watching the video and listening to the audio. When he or she has mastered the relevant small program test of the elementary course, he or she can try to learn the intermediate course. Even learners with dyslexia can challenge themselves to reach the same level as their peers after completing a series of courses. Flipped classroom method increases interest in learning by learners because it allows learners to absorb information step by their own pace during the extracurricular preparation time. They have more time to communicate or discuss with teachers in the classroom. Flipped learning turns traditional lectures into Learner-centered education.

\section{DISCUSSIONS}

Under the influence of the COVID-19 pandemic, online education is undoubtedly a good way for learners. The flipped classroom can cultivate students' independent learning ability and respect the individual differences of students. The flipped classroom is truly student-centered, subverting traditional teaching concepts and teaching students in accordance with their aptitude [19]. To effectively implement the flipped learning model, students should be encouraged and motivated to use video, animation, simulation, interaction, and other methods for extracurricular learning [49]. People with dyslexia can master knowledge more effectively through audiovisual learning and software programs in flipped classrooms.

Flipped classroom teaching methods flexibly combined with video, audio, and small operations such as auxiliary program, make reading disabilities through a lot of visual and auditory stimuli, and get his peers' knowledge. They can make up for what they can't learn in one class by taking repeated classes outside of school. Learners with dyslexia are more active in flipped classes because they feel safer. The flipped classroom is helpful for the personalized development of students, especially for dyslexia learners, to adjust the course according to their own learning needs. Students with dyslexia can learn new knowledge repeatedly in the flipped classroom in the early stage and express their ideas skillfully in the flipped class. Finally, they can be more confident in a public class by face-to-face and offline courses after learning from the flipped classroom.

However, the biggest disadvantage of the flipped classroom for learners by dyslexic is that it is difficult to gather all dyslexic students in the same classroom. Subsequent investigations and studies have certain difficulties and require a relatively long time to verify the results. Since theoretical teaching takes place outside the classroom, students may not watch the videos prepared by the teacher, and it may be difficult for the teacher to understand whether the student is learning correctly or how much he or she has learned. Shukla, Bergmann, Enfield and Tiahrt al et. also pointed out these[41, 50-54]. A series of attendance measures need to be introduced to ensure that students receive flipped classroom education.

\section{CONCLUSION}

The main conclusion that can be drawn is that flipped classroom approach influences dyslexia, and flipped classroom approach can help learners with dyslexia to some extent. Flipped classrooms make learning easier for people with dyslexia through audiovisual stimulation. And flipped classroom also allows people with dyslexia to repeat classes according to their learning needs. With the opportunity to repeat lessons, 
dyslexics can absorb the same knowledge as their peers. Thus reducing the difference between dyslexic learners and normal learners, which can improve students' overall performance.

Future investigations are necessary to validate the kinds of future research needed to test the difference in the incidence of dyslexia between flipped class and traditional class, as well as the difference in the results presented by students in the original class after using the flipped class teaching method for two years.

\section{REFERENCES}

[1] M. Bruck, Word recognition and component phonological processing skills of adults with childhood diagnosis of dyslexia, Developmental Review, 1993, pp. 258-268, doi: 10.1006/drev.1993.1012

[2] J. Muñoz-Arteaga, Educational Pattern Classification Considering Dyslexia in Pupils at Elementary School, in IEEE Revista Iberoamericana de Tecnologias del Aprendizaje, 2020, pp. 76-85, doi: 10.1109/RITA.2020.2987708.

[3] T. Cuschieri, R. Khaled, V.E. Farrugia, H.P. Martinez, G.N. Yannakakis, The iLearnRW Game: Support for Students with Dyslexia in Class and at Home, 2014 6th International Conference on Games and Virtual Worlds for Serious Applications (VS-GAMES), 2014, pp. 1-2, doi: 10.1109/VS-Games.2014.7012167.

[4] N. Ouherrou, O. Elhammoumi, F. Benmarrakchi, J. El Kafi, A Heuristic Evaluation of an Educational Game for Children with Dyslexia, 2018 IEEE 5th International Congress on Information Science and Technology (CiSt), 2018, pp. 386-390, doi: 10.1109/CIST.2018.8596393.

[5] P. Tzouveli, A. Schmidt, M. Schneider, A. Symvonis, S. Kollias, Adaptive Reading Assistance for the Inclusion of Students with Dyslexia: The AGENT-DYSL Approach, 2008 Eighth IEEE International Conference on Advanced Learning Technologies, 2008, pp. 167171, doi: 10.1109/ICALT.2008.236.

[6] X. Liu, The shift from assessment based on differences to assessment based on cognitiveintervention in LD study, Chinese Journal of Special Education, 2003, pp. 69-74.

[7] X. Liu, D. Hou, S. Yang, W. Du, Research on the literacy cognitive deficit of developmental dyslexia children, 2004, pp. 7-11. doi: 10.16187/j .cnki.issn1001 -4918.2004.02.002
[8] L. Rello, A. Ali, J.P. Bigham, Dytective: Toward a Game to Detect Dyslexia, In Proc. of the 17th Int. ACM SIGACCESS Conference on Computers \& Accessibility, 2015, pp. 307-308. doi: $10.1145 / 2700648.2811351$

[9] I. Cook, K. Dakin, Basic Facts About DYSLEXIA \& Other Reading Problems. International Dyslexia Association, 2008.

[10] R.L. Peterson, B.F. Pennington, Developmental dyslexia, The Lancet, 2012, pp. 1990-2005.

[11] S.N. Saidah Sarpudin, S. Zambri, Web readability for students with Dyslexia: Malaysian case study, 2014 3rd International Conference on User Science and Engineering (i-USEr), 2014, pp. 192-197, doi: 10.1109/IUSER.2014.7002701.

[12] S. Thelijjagoda, M. Chandrasiri, D. Hewathudalla, P. Ranasinghe, I. Wickramanayake, The Hope: An Interactive Mobile Solution to Overcome the Writing, Reading and Speaking Weaknesses of Dyslexia, 2019 14th International Conference on Computer Science \& Education (ICCSE), 2019, pp. 808-813, doi: 10.1109/ICCSE.2019.8845396.

[13] W. Turner, K. Greaney, Defining Dyslexia, Journal of Learning Disabilities, 2009, pp. 229-243.

[14] N. Hahn, J.J. Foxe, S. Molholm, Impairments of multisensory integration and cross-sensory learning as pathways to dyslexia. Neuroscience and Biobehavioral Reviews, 2014, pp. 384-392. doi :10.1016/j.neubiorev.2014.09.007

[15] H.M. Al-Barhamtoshy, D.M. Motaweh, Diagnosis of Dyslexia using computation analysis, 2017 International Conference on Informatics, Health \& Technology (ICIHT), 2017, pp. 1-7, doi: 10.1109/ICIHT.2017.7899141.

[16] D. Talsma, D. Senkowski, S. Soto-Faraco, M.G. Woldorff, The multifaceted interplay between attention and multisensory integration. Trends in Cognitive Sciences, 2010, pp. 400-410. doi :10.1016/j.tics.2010.06.008

[17] X. Liu, X. Liu, X. Xu, Comparative study of visual memory of reading disabled and normal children, 2004, pp. 246-249. doi :10.16128/j.cnki.10053611.2004.03.008

[18] A.A. Francisco, M.A. Groen, A. Jesse, J.M. McQueen, Beyond the usual cognitive suspects: The importance of speechreading and audiovisual temporal sensitivity in reading ability. Learning and Individual Differences, 2017, pp. 60-72. doi: 10.1016/j.lindif.2017.01.003 
[19] J. Yuan, R. Xing, W. Zhang, Essence of flipped classroom teaching model and influence on traditional teaching, 2014 IEEE Workshop on Electronics, Computer and Applications, 2014, pp. 362-365, doi: 10.1109/IWECA.2014.6845632.

[20] D.J. Tune, M. Sturek, D.P. Basile, Flipped classroom model improves graduate student performance in cardiovascular, respiratory, and renal physiology. Advan in Physiol. Edu. 2013, pp. 316-320. doi: 10.1152/advan.00091.2013

[21] E. Mele, A. Tatsiopoulou, A. Ktena, Gamifying Elearning Course Content, 2020 9th Mediterranean Conference on Embedded Computing (MECO), 2020, pp. 1-4, doi: 10.1109/MECO49872.2020.9134195.

[22] T. Shindina, N. Kniazena, N. Usmanova, N. Orlova, E-Learning: Experience and New Challenges, $2020 \mathrm{~V}$ International Conference on Information Technologies in Engineering Education ( Inforino ), 2020, pp. 1-4, doi: 10.1109/Inforino48376.2020.9111846.

[23] C. Shpannagel, Designing in-class activities in the inverted classroom model, in the 2nd German ICM-Conference, 2013, pp. 113-120. doi: $10.1524 / 9783486781274.113$

[24] K. Umezawa, T. Ishida, M. Nakazawa, S. Hirasawa, Evaluation of Grouped Flipped Classrooms Compared with Three-Year Actual Classes Using a Questionnaire, 2020 IEEE International Symposium on Accreditation of Engineering and Computing Education (ICACIT), 2020, pp. 1-4, doi: 10.1109/ICACIT50253.2020.9277678.

[25] M.A. Trpkovska, L.A. Bexheti, B. Cico, Practical Experience of Applying the Flipping Learning Model in a Master Course at SEEU, in International Conference on e-Learning, 2016, pp. 162-167.

[26] C. Latulipe, A. Rorrer, B. Long, Longitudinal data on flipped class effects on performance in cs1 and retention after cs1, in Proceedings of the 49th ACM Technical Symposium on Computer Science Education, 2018, pp. 411-416. doi: $10.1145 / 3159450.3159518$

[27] E.M. Bakheet, A.M. Gravell, Would Flipped Classroom be My Approach in Teaching Computing Courses: Literature Review, 2021 9th International Conference on Information and Education Technology (ICIET), 2021, pp. 166-170, doi: 10.1109/ICIET51873.2021.9419631.
[28] L. Mishra, T. Gupta, A. Shree, Online teachinglearning in higher education during lockdown period of COVID-19 pandemic, International Journal of Educational Research Open, 2020, Article 100012, doi: 10.1016/j.ijedro.2020.100012

[29] M. Kast, G.-M. Baschera, M. Gross, L. Jancke, M. Meyer, Computer-based learning of spelling skills in children with and without dyslexia. Annals of Dyslexia, 2011, pp. 177-200. doi: IO.1007/s11881-011-0052-2.

[30] S.S. Abdul Hamid, N. Admodisastro, A. Kamaruddin, A study of computer-based learning model for students with dyslexia, 2015 9th Malaysian Software Engineering Conference (MySEC), 2015, pp. 284-289, doi: 10.1109/MySEC.2015.7475234.

[31] X. Liu, W. Du, B. Wang, S. Wu, Study on characteristics of visual short-term memory ability of Chinese-speaking dyslexic children, Chinese Journal of Special Education, 2005, pp. 48-55.

[32] P. Peng, C. Wang, S. Tao, C. Sun, The Deficit Profiles of Chinese Children with Reading Difficulties: a Meta-analysis. Educational Psychology Review, 2017, pp. 513-564.

[33] Y. Ruan, C. Qi, X. Liu, Multisensory training as a teaching method on Chinese children with spelling difficulties, Chinese Journal of Clinical Psychology, 2018, pp. 824-825. doi: 10.16128/j.cnki.1005-3611.2018.04.042

[34] J. Bishop, M.A. Verleger, The Flipped Classroom: A Survey of the Research, in 2013 ASEE Annual Conference \& Exposition, 2013, pp. 1-18. https://peer.asee.org/22585

[35] N.T.T. Thai, B. De Wever, M. Valcke, The impact of a flipped classroom design on learning performance in higher education: Looking for the best blend of lectures and guiding questions with feedback, Computers and Education, 2017, pp. 113-126. doi: 10.1016/j.compedu.2017.01.003

[36] V. Ilie, The Flipped Classroom. In: Education Quarterly Reviews, 2019, pp. 395-407. doi: 10.31014/aior.1993.02.02.72

[37] B. Lee, Students' perceptions of using a flipped classroom instructional model in an ESP course, 2017 International Conference on Applied System Innovation (ICASI), 2017, pp. 1562-1564, doi: 10.1109/ICASI.2017.7988226.

[38] Educause, 7 things you should know about flipped classrooms, 2012, Retrieved from http://net.educause.edu/ir/library/pdf/ ELI7081.pdf 
[39] S. Uchiyama, H. Okumoto, M. Yoshida, Y. Ichikawa, K. Umemura, Usefulness of Instructor Annotations on Flipped Learning Preparation Video System, 2019 International Conference of Advanced Informatics: Concepts, Theory and Applications (ICAICTA), 2019, pp. 1-6, doi: 10.1109/ICAICTA.2019.8904173.

[40] S.B. Velegol, S.E. Zappe, E. Mahoney, The Evolution of a Flipped Classroom: Evidence-Based Recommendations, Advances in Engineering Education, 2015, n3. https://eric.ed.gov/?id=EJ1076140

[41] N.J. Shukla, E. Mcinnis, Flipped classroom: Success with first year mathematics students. International Journal on Social and Education Sciences (IJonSES), 2021, pp. 32-47. doi: 10.46328/ijonses.56

[42] M. Rigou, M. Xenos, S.M. Evangelou, Shifting the Flipped Classroom Online: Experiences from a Postgraduate Course on Usability Evaluation During COVID-19 Lockdown, 2021 IEEE Global Engineering Education Conference (EDUCON), 2021, pp. 272-277, doi: 10.1109/EDUCON46332.2021.9453998.

[43] R. Brünken, S. Steinbacher, J.L. Plass, D. Leutner, Assessment of cognitive load in multimedia learning using dual-task methodology, Experimental Psychology, 2002, pp. 109-119. doi: 10.1027/1618-3169.49.2.109

[44] E.-S.M. El-Alfy, Using Mashup and Web 2.0 to Foster Inquiry-Based Flipped Classroom in Online Teaching of Technical Curriculum: A Case Study, 2020 Sixth International Conference on e-Learning (econf), 2020, pp. 28-34, doi: 10.1109/econf51404.2020.9385480.

[45] Z. Zainuddin, M. Attaran, Malaysian students' perceptions of flipped classroom: a case study, Innovations in Education and Teaching International, 2015, pp. 665-669. doi: $10.1080 / 14703297.2015 .1102079$

[46] D. Schultz, S. Duffield, S.C. Rasmussen, J. Wageman, Effects of the Flipped Classroom Model on Student Performance for Advanced Placement High School Chemistry Students. Journal of Chemical Education, 2014, pp. 1334-1339. doi:10.1021/ed400868x

[47] C.M. Corredor, R.F. Gesa, Framework for Intervention and Assistance in University Students with Dyslexia, 2012 IEEE 12th International Conference on Advanced Learning Technologies, 2012, pp. 342-343, doi: 10.1109/ICALT.2012.170.
[48] J. Zhang, Y. Wang, B. Zhang, Introducing a New Teaching Model: Flipped Classroom, Journal of Distance Education, 2012, pp. 46-51.

[49] F.S. Say, F.S. Yildirim, Flipped Classroom Implementation in Science Teaching. International Online Journal of Education and Teaching (IOJET), 2020, pp. 606-620. http://iojet.org/index.php/IOJET/article/view/759

[50] J. Bergmann, A. Sams, Flip Your Classroom Reach Every Student in Every Class Every Day. In Get Abstract Compressed Knowledge, 2014. doi: 10.1111/teth. 12165

[51] J. Enfield, The Value of Using an E-Text in a Flipped Course. TechTrends, 2016. doi: $10.1007 / \mathrm{s} 11528-016-0100-1$

[52] D. Ramirez, C. Hinojosa, F. Rodriguez, Advantages and Disadvantages of Flipped Classroom: Stem Students ${ }^{\text {ee }}$ Perceptions. Iceri 2014: 7Th International Conference of Education, Research and Innovation. 2014. doi: 10.13140/RG.2.1.2430.8965

[53] R. Talbert, Inverting the Linear Algebra Classroom. PRIMUS, 2014. doi: 10.1080/10511970.2014.883457

[54] T. Tiahrt, J.C. Porter, What Do I Do with this Flipping Classroom: Ideas for Effectively Using Class Time in a Flipped Course. Business Education Innovation Journal, 2014. doi: 10.1017/CBO9780511921247.020 